\title{
Cycles and Intervals in Hen Egg Laying
}

\author{
Vyacheslav I. Shcherbatov and Artem G. Shkuro* \\ Kuban State Agrarian University named after I.T. Trubilin, 350044 Kalinina str., 13, Krasnodar, Russia
}

\begin{abstract}
The article is devoted to the cyclicity of hen's egg-laying, which determines the egg production of poultry during the established period. The characteristic features of the alternation of egg-laying cycles and the intervals between them on the example of egg's cross Lohmann Brown are analyzed. The necessity to reduce the periodicity and time of the intervals between the cycles was identified. A negative correlation between egglaying intensity and egg weight was revealed. At the same time, there is a high correlation relationship between the intensity of egg production and the duration of cycles. In this article, the tendency of decreasing egg weight with increasing duration of laying cycles was established.
\end{abstract}

The egg-laying rate is one of the main indicators characterizing the egg productivity of poultry. The entire history of the creation and improvement of breeds and then lines and crosses is directly related to the selection for the expression of this trait. Undoubtedly, the issues associated with the selection of birds for high egg production were of interest to domestic and foreign researchers. So, in works of H. F. Kushner (1973), it is shown, that egg production hens for a year is inherited at a level of $h^{2}=0,27$, the duration of laying of eggs $(0,35)$ and length of a cycle of oviposition $\mathrm{h}^{2}=0,40$ have greater heritability [2].

The positive ratio between egg production and cycle length is also different for meat hens.

The coefficients of inheritance of cycle length in meat hens of the Cornish breed were 0.36 and in the Plimutrock breed 0.6. It was found that the number of eggs per cycle varied from 1 to 14 in the Cornish breed chickens. At the same time, the authors consider it inexpedient to carry out the selection on the length of the first cycle because of low egg production during this period [1,4,6,7].

Intensive selection for the egg production period (12 months of use for egg hens) allowed to reach the egg production rate of modern crosses of 350 eggs per laying hen. In the future, when the breeding plateau for this indicator is reached, work is actively carried out to increase the duration of laying eggs, i.e. the period of its productive use. The results of this work are impressive when in 80 weeks of life hens lay about 500 eggs.

In this regard, the development of directions to assess and predict the egg production capacity of chickens at an early age, as well as the creation of new methods of their breeding for high egg production, is relevant topic for poultry. A reconnaissance experiment was carried out in the conditions of the Department of Farm Animal Breeding and Zootechnology of Kuban State Agrarian University when keeping the Lohmann Braun cross hens in individual cages. Egg production was recorded from the age of the beginning of

\footnotetext{
*Corresponding author: archi17@inbox.ru
} 
oviposition up to 500 days of hens' life. Video observation was carried out with Logitec video cameras and PCs. The time of laying eggs during the light period of the day was recorded with an accuracy of up to 1 minute. The light regime was intermittent during laying hens' housing.

The results of individual recording of egg-laying rate were used to determine the intensity of egg-laying for each month and the entire production period, the number of egg-laying cycles and intervals, and their duration. The weight of laid eggs was counted daily.

According to the results of egg production, the group of hens was divided into highly productive layers with egg production of 300 and more eggs per season and low productive layers with less than 300 eggs per 500 days of life.

The entire chicken population was structurally comprised of $80 \%$ of high-yielding hens and $20 \%$ of low-yielding laying hens.

High-yielding hens outperformed low-yielding hens in terms of the egg-laying rate at all ages. High-yielding hens reached commercial maturity (egg production of 50\%) at 138 days of age, while low-yielding hens reached it at 148 days of age. Heifers with high laying performance reached peak laying one month earlier and the duration of the laying plateau was longer than 6 months. At the same time, low-yielding hens were characterized by a short duration of the egg-laying plateau, not more than 2 months, and a sharp decrease in egglaying by the end of the season.

The intensity of egg production during the productive period in high-yielding laying hens was $92.6 \%$, which is $27.4 \%$ higher than in low-yielding hens.

The egg production of hens during the productive period is characterized by such indicators as laying cycles and intervals between them. A cycle is a period during which the hens lay without interruption, and an interval is an interval of time when the hens do not lay $[3,4,8,10]$.

Table 1 shows the research data on cycles and intervals in laying hens with high and low egg production.

Table 1. Cycles and intervals in egg-laying hens period with different productivity

\begin{tabular}{|c|c|c|c|c|c|c|}
\hline The group of laying hens & 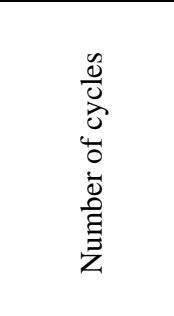 & 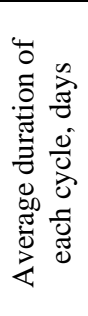 & 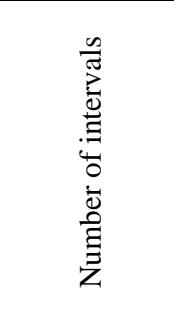 & 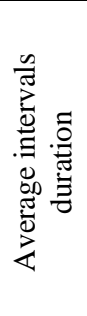 & 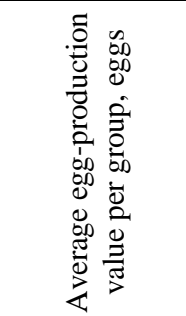 & 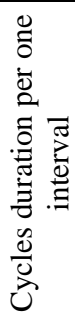 \\
\hline $\begin{array}{l}\text { High-yielding laying hens } \\
\text { (300 eggs or more) }\end{array}$ & $18,6 \pm 2,27 * *$ & 17,6 & $23,6 \pm 2,68 * *$ & 1,2 & $328,4 \pm 2,69 * *$ & 14,7 \\
\hline $\begin{array}{l}\text { Low-yielding laying hens } \\
\text { (less than } 300 \text { eggs) }\end{array}$ & $39 \pm 10,73$ & 5,9 & $121,8 \pm 24,4$ & 29,4 & $230,3 \pm 24,41$ & 0,2 \\
\hline
\end{tabular}

$(* * \mathrm{P}<0,99)$

Thus, with the average duration of cycles of 17.6 days in the group, the egg production of high-yielding laying hens was higher by $30.0 \%$ than in the group of low-yielding. Lowyielding hens are characterized by a large number of intervals - 29.4 days. The difference in the duration of cycles per one day of the interval is very noticeable. For high-yielding hens, it is more than 72 times higher than for low-yielding laying hens. For high-yielding hens, the duration of intervals varies between 1 and 2 days. The frequency and duration of intervals for all laying hens regardless of their productivity were minimal at the beginning of laying and when reaching the laying plateau. 
Based on the results of studies on cycles and intervals in laying hens, we developed an egg-laying cyclicity index, which shows the effect of the number of intervals in laying hens on the egg production capacity of laying hens.

Egg-laying cyclicity index is calculated by the formula:

$$
\mathrm{F}=\frac{\text { egg-laying }}{n}
$$

where

F - egg-laying cyclicity index;

$\mathrm{n}$ - number of intervals for one period

In the second half of the productive period, the number of laying cycles increased, with an increase in the number of intervals and their duration. These changes are most contrasting for hens with a low-yielding factor per season.

In high-yielding hens, the egg-laying cycle lasts up to 3-4 months without interruption. Interruptions in egg-laying in such laying hens for the whole period were from 1 to 4 days per month.

Figures 1 and 2 show the obtained data on egg-laying intensity and the duration of intervals for high and low-yielding hens.

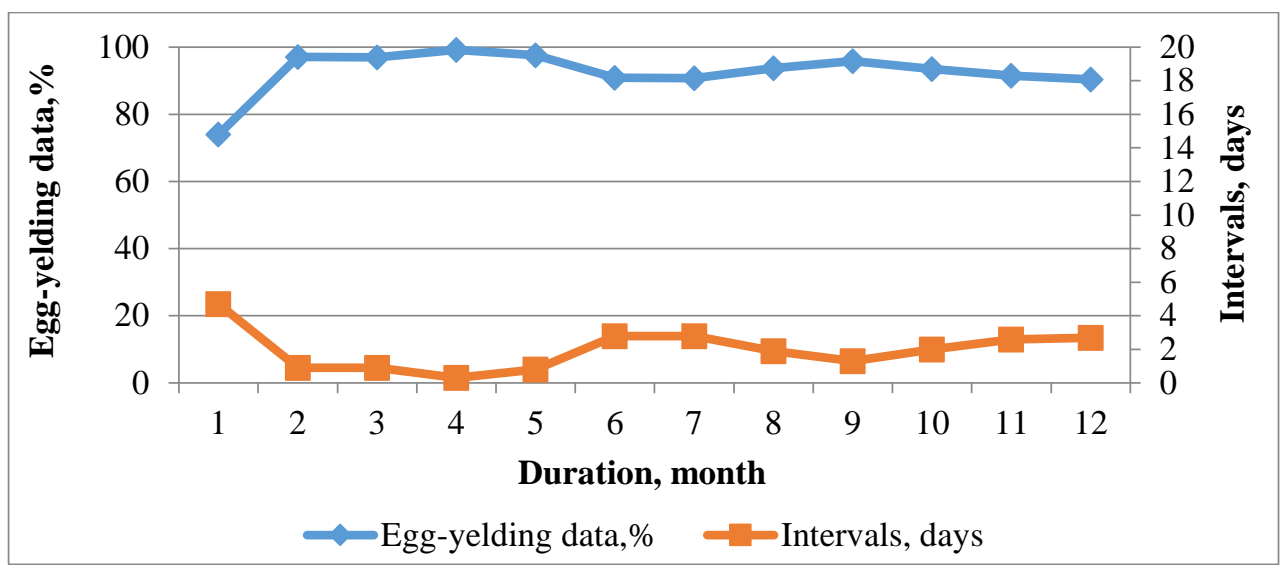

Fig. 1. Dynamics of egg production and intervals of high-yielding laying hens

As the productivity plateau decreases, the number of intervals increases. In high-yielding hens, this period falls at 5-8 months and the duration of intervals for the entire production period was within 2-4 days. Low-productive layers were also characterized by an increase in the number and duration of intervals with a decrease in egg production from the 5th month of the production period. At the same time, the dynamics of changes in these indicators are most pronounced. At the end of the productive period, the number and duration of intervals sharply increase with a decrease in the intensity of egg-laying. 


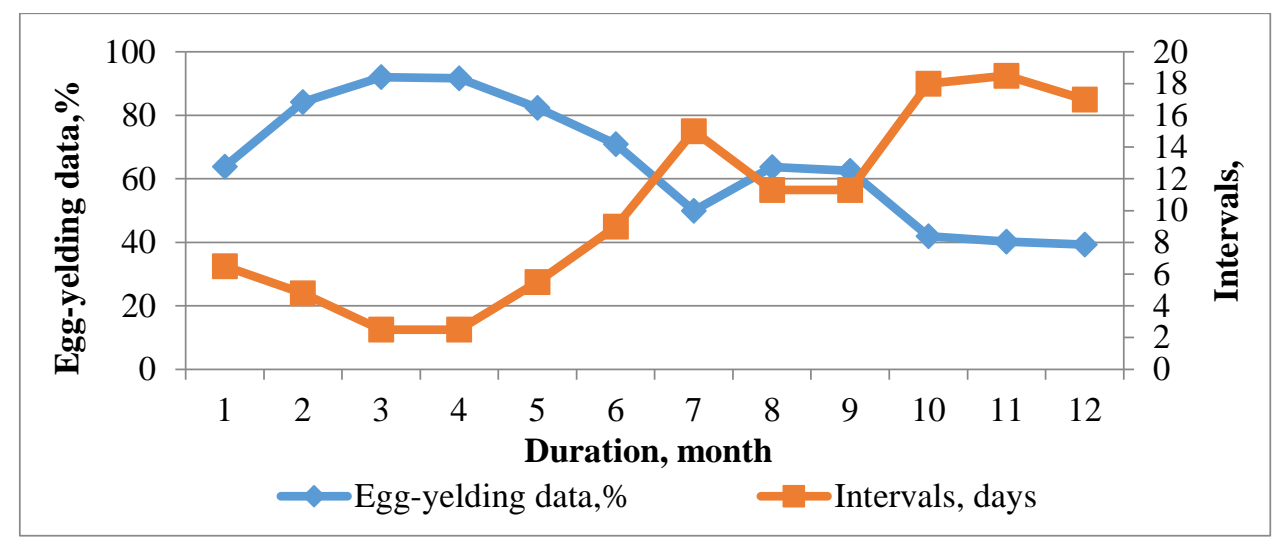

Fig. 2. Dynamics of egg production and intervals of low-yielding laying hens

The presented graphs clearly show that the number of intervals is directly related to the intensity of oviposition. When the intensity of oviposition decreases, the number of intervals and their duration increase. Both the duration and the duration of the intervals in the same bird tend to be rhythmically repetitive. It has been determined that the longer the cycles, the shorter the intervals, respectively, the higher the bird's productivity $[5,9,11]$.

Most egg-laying hens are distinguished by long laying cycles and short egg laying intervals. Thus, layers with an egg production capacity of more than 300 eggs per productive period had an average duration of intervals of 23.6 days. And with low egg production of more than 121 days.

The dynamics of egg-yielding of hens and the duration of intervals is shown in Figure 3.

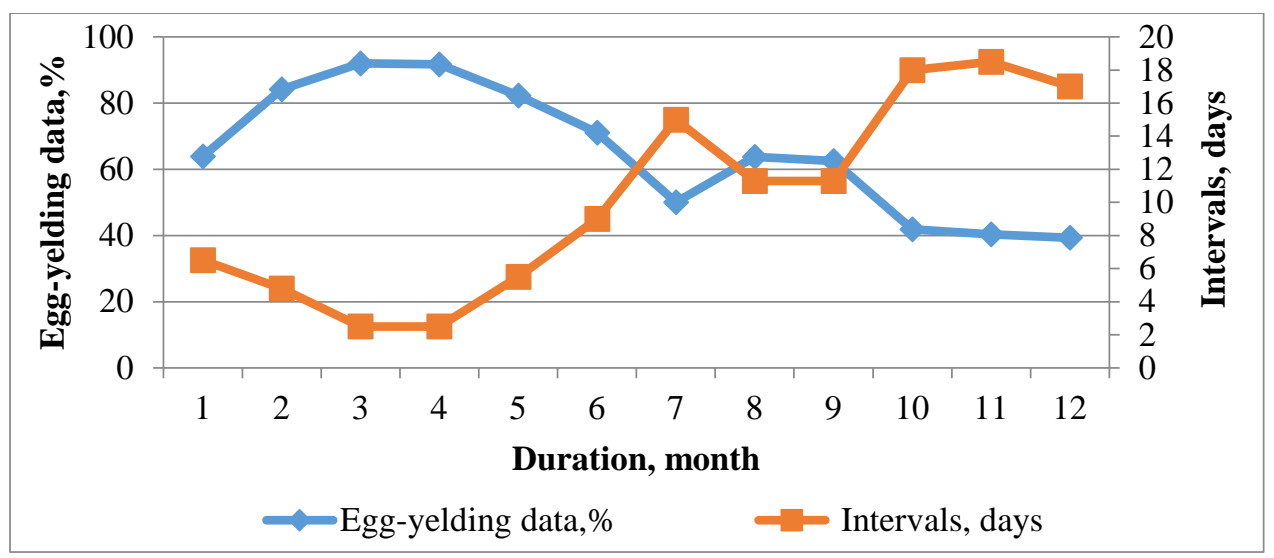

Fig. 3. The dynamics of egg-yielding of hens and the duration of intervals during period of productivity

The relationship between egg production and the duration of intervals in laying hens is linear. At the same time, hens with high productivity are characterized by long cycles. Thus, some of the highly productive hens had cycled with the duration of more than 100 days, i.e. more than 3-4 months the hens were laying without intervals and the intervals of these hens did not exceed 1-2 days between the cycles. The correlation coefficient between the hens' egg production rate and the number of intervals $r=-0.99$, but the higher the number of intervals, the longer their period $(+0.87)$, between the egg production rate and the number of cycles 0.66 ; between the egg production rate and the duration of cycles +0.65 . Duration of cycles is negatively related to the number of cycles $r=-0.7$. Thus, the egg-laying rate depends more on the number of intervals in laying eggs than on the duration of cycles. In 
low-productive hens, the decrease in egg-laying rate is associated not only with an increase in the number of intervals but also with an increase in their duration.

A negative correlation between egg-laying intensity and egg weight was revealed (table 2).

Table 2. Egg-laying intensity and egg weight in hens with different productivity.

\begin{tabular}{|c|c|c|c|c|c|c|c|}
\hline \multirow{2}{*}{\multicolumn{2}{|c|}{ Group }} & \multicolumn{5}{|c|}{ Age, days } & \multirow{2}{*}{$\mathrm{r}$} \\
\hline & & 161 & 210 & 360 & 420 & 460 & \\
\hline \multirow{2}{*}{ 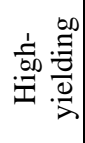 } & $\begin{array}{l}\text { Egg-laying } \\
\text { intensity, \% }\end{array}$ & 96,5 & 99,2 & 95,8 & 91,5 & 90,4 & \multirow{2}{*}{$-0,42$} \\
\hline & Egg's mass, g & 53,1 & 55,0 & 60,6 & 59,8 & 59,5 & \\
\hline \multirow{2}{*}{ 党: } & $\begin{array}{l}\text { Egg-laying } \\
\text { intensity, \% }\end{array}$ & 83,5 & 91,7 & 62,5 & 40,3 & 39,3 & \multirow{2}{*}{$-0,77$} \\
\hline & Egg's mass, g & 53,5 & 56,7 & 60,6 & 60,9 & 61,9 & \\
\hline
\end{tabular}

The biological rhythm of laying hens is cyclic and consists of alternating egg-laying cycles and intervals between them. The laying rate of hens during the production period depends on the number of laying cycles and their duration.

High-yielding hens are characterized by a smaller number of laying cycles with short intervals between the cycles. The relationship between the egg production rate of hens and the duration of intervals is linear.

There is a tendency of increasing in egg weight with decreasing intensity of egg-laying.

\section{References}

1. A. Y. Egorova, L.V. Shakhnova, Livestock in Russia, Selection of meat hens according to egg laying rate, 2, (2013)

2. H. F. Kushner, Agr. Abroad, Genetic basis of poultry breeding, 6, 17 (1973)

3. A. G. Shkuro, Mat. of international. sci. conf of 95 anniv. of KubSAU, Biological rhythms of laying hens kept in cage batteries, 238, (2017)

4. A. G. Shkuro, Sci. support of agro-ind. complex, Biological rhythms of laying hens, 61, (2019)

5. A. G. Shkuro, Article collection called problems in husbandry, Time is a breeding trait in poultry, 102, (2018)

6. V. I. Scherbatov, Poultry, Influence of egg's mass of meat-chikens on quality of incubation, 4, 17, (2019)

7. V. I. Scherbatov, A. G. Shkuro, T. I. Pakhomova, Poultry, Chicken's egg-laying rhythms, 9-10, 75 (2019)

8. V. I. Scherbatov, Poultry and its products, Rhythms of laying hens kept in cage batteries, 3, 58, (2016)

9. V. I. Scherbatov, A. G. Shkuro, Modern prob. in animal husb.: state, solutions, prospects, Circadian rhythms of egg-laying hens, 308, (2019)

10. L. B. Astheimer, Long laying intervals: possible mechanism and its implications, 102, 401, (1985)

11. F. Halberg, Zeitschriit fur Vitamin, Hormon und Fermentforschhung, Physiologic 24hour periodicity: General and procedural considerationswith reference to the adrenal cycle, 10, 225, (1959) 